\title{
SYNTHESIS AND CHARACTERIZATION OF ALGINATE- CELLULOSE XANTHATE BEADS FROM CORN STALK WITH NACL AS POROGEN
}

\author{
Wahyu Adhi Putra Rohmatullah, Eny Yulianti, Lilik Miftahul Khoiroh, Rif’atul Mahmudah \\ Department of Chemistry, Faculty of Science and Technology, State Islamic University Maulana \\ Malik Ibrahim Malang, Jl. Gajayana 50, Malang, East Java, Indonesia 65144
}

\begin{abstract}
In this study, the synthesis of porous beads from corn stalks was carried out. The cellulose extracted from corn stalks was converted into cellulose xanthate and combined with alginate to form porous alginate-cellulose xanthate beads by the ionic gelation method. This study attempted to use sodium chloride $(\mathrm{NaCl})$ as a porogen and zinc acetate as a crosslinker. Beads were characterized to determine the porosity, swelling properties, and functional groups using Fourier Transform Infra-Red (FTIR). The geometry of beads was analyzed by optical microscopy, and its surface morphology was analyzed by Scanning Electron Microscopy-Energy Dispersive Xray (SEM-EDX). The results showed that corn stalks as agricultural waste material could be used to synthesize porous beads material. The swelling and porosity of beads increased with increasing concentration of $\mathrm{NaCl}$. The presence of porogen has increased beads formation. The results demonstrate the crosslinks between zinc acetate and alginate were successfully characterized using FTIR. $\mathrm{NaCl}$ concentration of $9.5 \%$ resulted in the highest swelling properties $(52.80 \%)$ and porosity $(81.4 \%)$ of the beads.
\end{abstract}

Keywords: synthesis of cellulose xanthate, swelling, corn stalk, porosity

*Corresponding author:

Department of Chemistry, Jalan Gajayana 50, Malang 65144, East Java, Indonesia

E-mail. enyyulianti@kim.uin-malang.ac.id

\section{Introduction}

Corn stalks are an agricultural waste that has potential as a biopolymer material. Boufi \& Achraf (2016) explained that corn stalks contain $69 \%$ cellulose and $31 \%$ hemicellulose after a delignification process. The high cellulose content in corn stalks makes them suitable for producing beads. Cellulose is an abundant, biodegradable, and non-toxic material, which attracted researchers to use cellulose as a primary material for making beads. Research conducted by Sönmez et al. (2016) reported that the addition of cellulose in alginate/cellulose composite beads could increase the absorption of beads against $\mathrm{Cu}^{2+}$.

Cellulose is a long-chain polysaccharide consisting of $\beta$-D-glucopyranose units joined by $\beta-1.4$ glycosidic (Hokkanen et al., 2016). The absence of branching in the cellulose chain causes cellulose to be semicrystalline, which has both an amorphous phase and a crystal phase (Harmsen et al., 2010). Cellulose has a reactive group in the form of hydroxyl $(-\mathrm{OH})$, which is distributed evenly on the cellulose side, thus allowing the formation of hydrogen bonds between cellulose molecules (Harmsen et al., 2010). Hydrogen bonds in cellulose are causing it to be insoluble in water and other organic solvents directly and, it needs to be converted into cellulose xanthate to reduce hydrogen bonds between cellulose. Cellulose xanthate is made by the addition of $\mathrm{NaOH}$ and $\mathrm{CS}_{2}$ reagent. The addition of these compounds will replace the hydroxyl group on cellulose with the xanthate group. Alginate is a natural anionic polymer from brown seaweed. Besides having good biocompatibility, alginate can also improve mechanical strength, has low toxicity, and is inexpensive. In general, alginate is known as the overall part of the linear copolymers containing block residues (1.4) -d-mannuronate (M) and $\alpha$-l-guluronate (G) (Lee and Mooney, 2012).

Alginate and cellulose can be used as the base for beads making. Beads from biopolymers can be used as drug carriers, planting media, and adsorbents. One of the commonly applied 
methods for beads formation is the ionic gelation method. The ionic gelation method is based on the formation of hydrogels influenced by crosslinked agents (Patil et al., 2010). Sönmez et al. (2016) explained the mechanism of zinc acetate as a crosslinker. Crosslinking is formed between the - $\mathrm{COO}$ group - from the residual guluronic alginate acid, which establishes an "egg-box" model with the negatively charged $\mathrm{Zn}^{2+}$ cation. The egg-box model causes the beads to have high mechanical properties (Lin et al., 2012).

The adsorption capacity of beads can be increased through the use of a pore-forming agent or a porogen. The commonly used porogens are $\mathrm{KCl}, \mathrm{Na}_{2} \mathrm{SO}_{4}, \mathrm{NaHCO}_{3}, \mathrm{~K}_{2} \mathrm{HPO}_{4}$ $\mathrm{CaCO}_{3}$, and $\mathrm{NaCl}$. The advantage of $\mathrm{NaCl}$ as a porogen is that the resulting surface area and the absorption capacity are higher compared to the product of solvating porogen (Mane, 2016). Additionally, the availability of $\mathrm{NaCl}$ is abundant and relatively inexpensive.

The purpose of this research is to make beads based on alginate and cellulose xanthate with the addition of $\mathrm{NaCl}$ as porogen. Cellulose xanthate used in this study came from the isolation of cellulose from corn stalks waste, which was synthesized into cellulose xanthate with the addition of $\mathrm{NaOH}$ and $\mathrm{CS}_{2}$. Beads formed are then characterized for their swelling properties, changes in diameter, and morphology to determine the effect of the use of $\mathrm{NaCl}$ porogen on beads.

\section{Materials and Methods}

\section{Material}

Corn stalks were obtained from the district of Malang, East Java, Indonesia. All chemicals used in this study were of analytical grade, including the sodium hydroxide, chloride acid, acetic acid, zinc acetate, sulfuric acid, sodium chloride, carbon disulfide, ethanol were purchased from Merck (Germany), and sodium alginate was from PhytoTechnology Laboratories (USA).

\section{Extraction of Cellulose}

The process of bead production is shown in Figure 1. Firstly, corn stalks were cleaned and sun-dried. Dry samples were crushed into powder with a size of 100 mesh, then put into the oven for $24 \mathrm{~h}$ at $90{ }^{\circ} \mathrm{C}$. Fifty grams of corn stalks powder were immersed in $1,000 \mathrm{~mL}$ $\mathrm{NaOH} 10 \%(\mathrm{w} / \mathrm{v})$ at $80{ }^{\circ} \mathrm{C}$ for 90 mins, then washed several times with distilled water and press-filtered. The resulting pulp was treated with $200 \mathrm{~mL} \quad \mathrm{NaClO}_{2} \quad 1 \%(\mathrm{v} / \mathrm{v})$, then $\mathrm{CH}_{3} \mathrm{COOH} 10 \%(\mathrm{v} / \mathrm{v})$ was added until $\mathrm{pH} 5$ at $75^{\circ} \mathrm{C}$ for $1 \mathrm{~h}$. After that, it was washed with distilled water until the $\mathrm{pH}$ became neutral, then it was press-filtered. Cellulose obtained was hydrolyzed with $5 \%(\mathrm{v} / \mathrm{v}) \mathrm{HCl}(1: 20)$ at $95^{\circ} \mathrm{C}$ for $1 \mathrm{~h}$ to obtain dispersed microfiber.

\section{Synthesis of Cellulose Xanthate}

Five grams of cellulose were immersed in $40 \mathrm{~mL} \mathrm{NaOH} 20 \%(\mathrm{~b} / \mathrm{v})$ for $3 \mathrm{~h}$. It was subsequently press-filtered and kept for $60 \mathrm{~h}$ at room temperature for aging. The obtained alkaline cellulose was reacted with $2.5 \mathrm{~mL}$ $\mathrm{CS}_{2}$, and the sample was homogenized using a shaking incubator (shaking rate $150 \mathrm{rpm}$ ) at $25{ }^{0} \mathrm{C}$ for $3 \mathrm{~h}$ to acquire cellulose xanthate. After that, the suspension was dissolved in 30 $\mathrm{mL} \mathrm{NaOH} \mathrm{6 \% (w/w)} \mathrm{(Wang} \mathrm{et} \mathrm{al.,} \mathrm{2013).}$

\section{Beads Shaping}

Sodium alginate $(0.5 \mathrm{gr})$ was dissolved in $12.5 \mathrm{~mL}$ aquademin and added with a few drops of $\mathrm{CH}_{3} \mathrm{COOH}$ until thoroughly dissolved, followed by the addition of cellulose xanthate with the ratio of alginate to cellulose xanthate of $1: 3$. Then porogen $\mathrm{NaCl}$ was added in varying concentrations of $3.3,6.5$, and $9.3 \%$ (designated as ACX-1, ACX-2, and ACX-3), whereas the beads without porogen are designated as ACX0 . Then each mixture was homogenized. As the solution formed, it was dripped using an $18 \mathrm{G}$ syringe needle into a solution of $5 \%(\mathrm{w} / \mathrm{v})$ of zinc acetate up to $100 \mathrm{~mL}$ and left for $24 \mathrm{~h}$. The beads formed were filtered (Suvachittanont and Pookingdao, 2013).

Filtered beads were washed in distilled water and put in the shaker at $150 \mathrm{rpm}$ for $48 \mathrm{~h}$, followed by soaking for $24 \mathrm{~h}$. The obtained beads were dried at $37{ }^{\circ} \mathrm{C}$ for $5 \mathrm{~h}$, and the swelling properties were determined (Tas, 2008). 

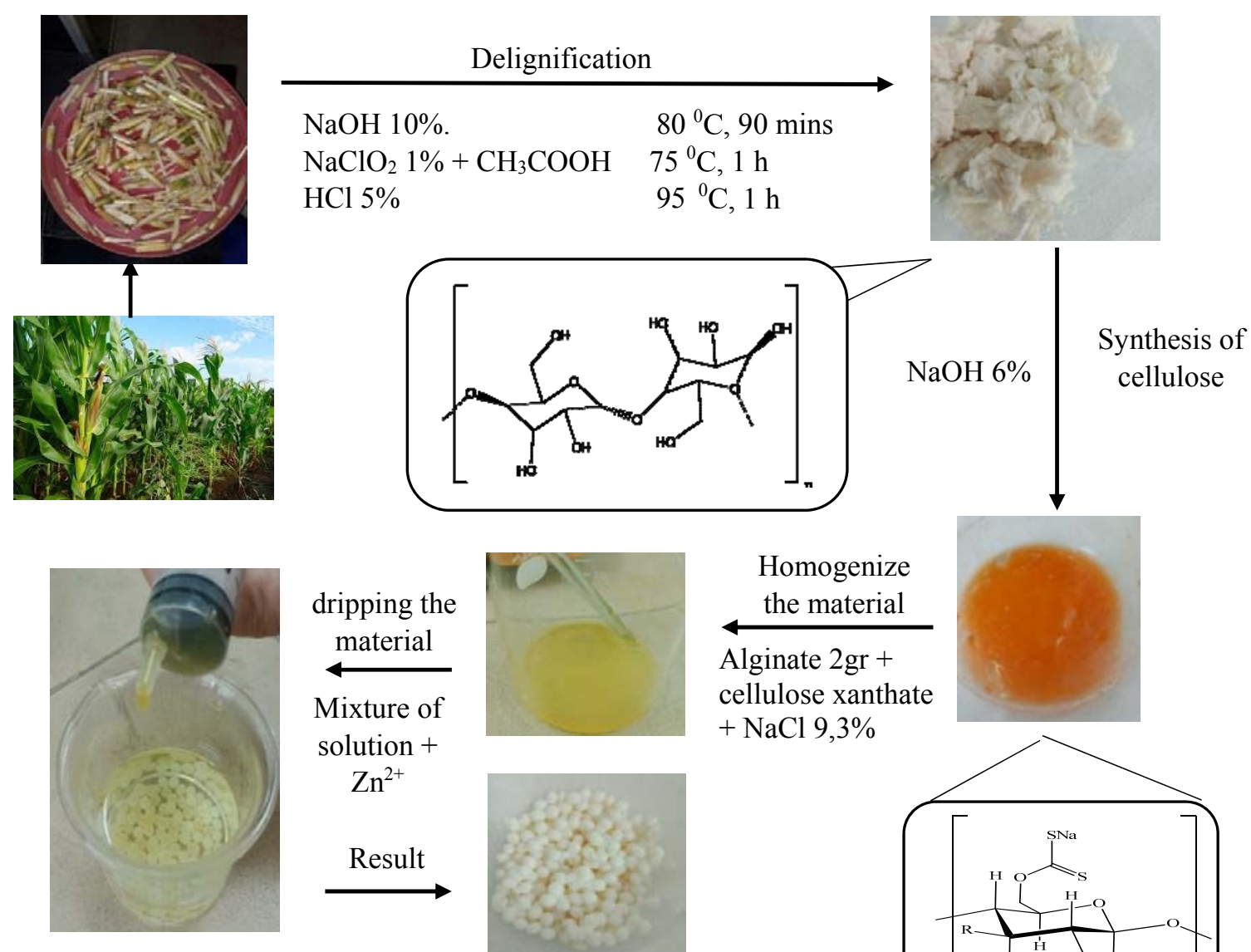

$$
\begin{gathered}
\text { solution }+ \\
\mathrm{Zn}^{2+}
\end{gathered}
$$
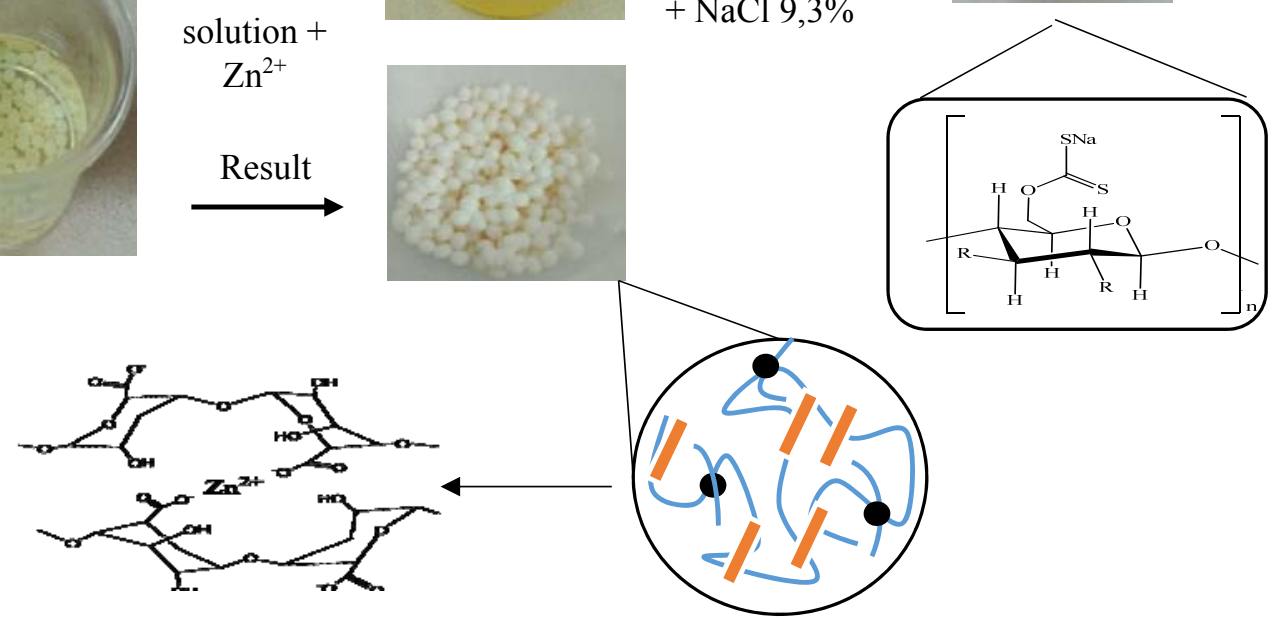

Figure 1. The schematic workflow for alginate-cellulose xanthate beads formation

\section{Lignin Content Analysis}

Analysis of lignin content in samples was carried out using Chesson's method (Datta, 1981). One gram of corn stalk powder (a) was added to $150 \mathrm{ml}$ distilled water and heated in a water bath at $100{ }^{\circ} \mathrm{C}$ for $2 \mathrm{~h}$. The mixture was filtered, and the residue was washed with hot water. After that, the sample was put in the oven, and weighed (b). The obtained residue was added into $150 \mathrm{ml} 0.5 \mathrm{M} \mathrm{H}_{2} \mathrm{SO}_{4}$ and refluxed for $2 \mathrm{~h}$ at $100{ }^{\circ} \mathrm{C}$. The sample was subsequently filtered and washed to neutral $\mathrm{pH}$. Then the residue was put in the oven to achieve constant weight $(c)$. The resulting residue was soaked with $10 \mathrm{ml} \quad 72 \% \quad \mathrm{H}_{2} \mathrm{SO}_{4}$ at room temperature for $4 \mathrm{~h}$. Afterwards, the mixture was added to $150 \mathrm{ml} 0.5 \mathrm{M} \mathrm{H}_{2} \mathrm{SO}_{4}$ and refluxed for $2 \mathrm{~h}$ and filtered. Then the mixture was filtered, washed to neutral $\mathrm{pH}$, and put in the oven to obtain its constant weight (d). Finally, the solid was heated until it turned to ash and weighed (e). The calculations using Chesson's method are as follows:

$\%$ cellulose $=\frac{c-d}{a} \times 100 \%$

$\%$ lignin $=\frac{d-e}{a} \times 100 \%$ 


\section{Porosity and Swelling Analysis}

The porosity of the beads was determined by placing the beads in a test tube. Filled with $5 \mathrm{~mL}$ of ethanol (V1). Beads were soaked for $24 \mathrm{~h}$. The total volume following beads immersion was recorded (V2). The solvent trapped inside the beads' pores were removed, and the remaining amount of ethanol in the cylinder is indicated by (V3). Porosity $(\chi)$ was determined using the equation below (Eiselt et al., 2000) :

$\chi=\frac{(\mathrm{V} 1-\mathrm{V} 3)}{\mathrm{VT}} \mathrm{X} 100=\frac{\mathrm{V} 1-\mathrm{V} 3}{\mathrm{~V} 2-\mathrm{V} 3} \mathrm{X} 100$

The swelling of beads was identified by soaking $\pm 50 \mathrm{mg}$ of beads in $20 \mathrm{ml}$ of aquademin. Beads were weighed after $24 \mathrm{~h}$ of immersion. The swelling test is determined based on equation (4).

$$
\text { Swelling }=\frac{W t-W o}{W o} \times 100 \%
$$

Where Wt is the weight of beads after soaking, and Wo is the weight before soaking.

\section{Morphology Analysis}

SEM-EDX was used to observe the morphology and elements present on the surface of alginate-cellulose xanthate beads.

\section{Size Analysis}

Wet, dry, and swollen beads are characterized using an optical microscope. Differences in the size of the diameter of the wet, dry, swollen beads and their pore sizes were obtained by analyzing the captured images using Image-J software (Wu et al., 2017).

\section{Results}

\section{Cellulose Content}

The extraction of cellulose in corn stalks have been successfully carried out using $\mathrm{NaOH}$. The addition of $\mathrm{NaOH}$ to the sample can reduce lignin levels but could not entirely eliminate lignin (Table 1). Test results on microfiber cellulose samples showed that lignin was still present at $19.67 \%$.

Based on FTIR spectra of cellulose extracted from corn stalks (Figure 2a) there were absorptions observed at $3471 \mathrm{~cm}^{-1}(\mathrm{OH}$ stretching group), $2929 \mathrm{~cm}^{-1}$ (CH group), 1479 $\mathrm{cm}^{-1}\left(\mathrm{CH}_{2}\right) 1384$ (antisymmetric CO), 1045 $\mathrm{cm}^{-1}$ (COC groups), $870 \mathrm{~cm}^{-1}$ ( $\beta$-glycoside bonds), $664 \mathrm{~cm}^{-1}$ (stretching CC), and 1641 $\mathrm{cm}^{-1}$ ( $\mathrm{C}=\mathrm{O}$ group) (Zheng and Meng, 2016).

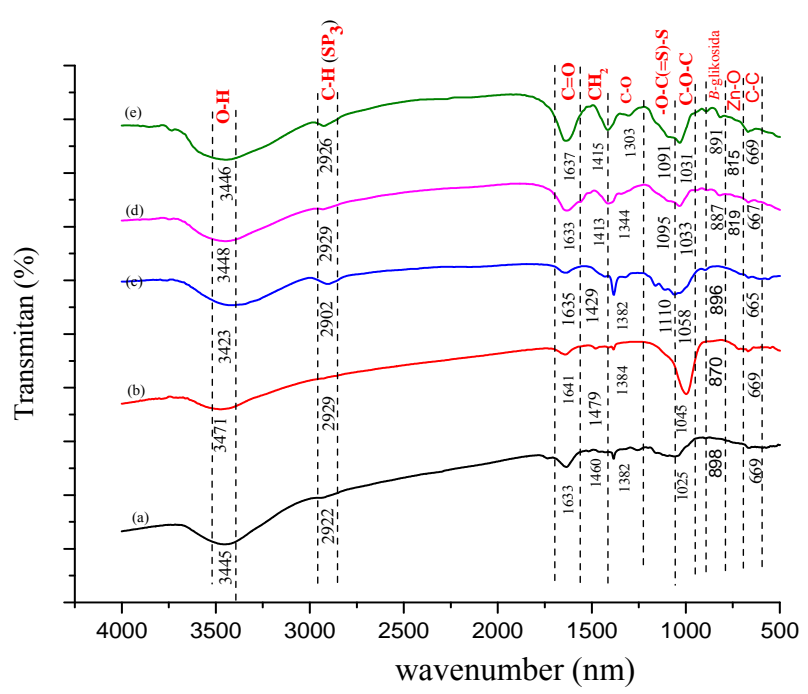

Figure 2. FTIR spectra of (a) corn stalk powder (b) microfiber cellulose (c) cellulose xanthate (d) ACX- 0 beads (e) ACX-3 beads

Table 1. Lignin and cellulose content in the sample

\begin{tabular}{lll}
\hline Sample & Cellulose (\%) & Lignin (\%) \\
\hline Cornstalk powder & 8.31 & 27.72 \\
$\begin{array}{l}\text { Microfiber } \\
\text { Cellulose }\end{array}$ & 38.43 & 19.67 \\
\hline
\end{tabular}

The FTIR of microfiber cellulose (Figure 2b) showed a reduction in absorption intensity at wave numbers 3471,2929 , and $1641 \mathrm{~cm}^{-1}$, which showed that the absorption of lignin compounds in the sample was reduced. On the other hand, the absorption at wave number $1045 \mathrm{~cm}^{-1}$ was shown to increase, demonstrating the absorption of C-O-C cellulose groups (Zheng and Meng, 2016). After the addition of $\mathrm{NaOH}$ and $\mathrm{CS}_{2}$ to cellulose, new uptake appeared in $1161 \mathrm{~cm}^{-1}$ and $1110 \mathrm{~cm}^{-1}$ (Figure 2c), which showed the typical uptake of cellulose xanthate $(-\mathrm{O}-\mathrm{C}(=$ S) -S). Additionally, the wide and high bending vibration absorption of $\mathrm{CH} 2$ (1429 $\mathrm{cm}^{-1}$ ) confirmed that a substitution reaction had occurred mainly in the C-6 hydroxyl cellulose group (Zheng \& Meng, 2016). FTIR spectra of beads (Figure $2 \mathrm{~d}$ and $2 \mathrm{e}$ ) showed a new absorption at $819 \mathrm{~cm}^{-1}$ for ACX-0 beads and $815 \mathrm{~cm}^{-1}$ or ACX-3, which was assumed to be an absorption of $\mathrm{Zn}-\mathrm{O}$ bonds. 
Shape, Diameter, and Weight of Swollen Beads and Their Porosity

Diameter measurement of wet and dry beads was performed using ImageJ software can be seen in Figure 3, whereas the shapes of dry beads are shown in Figure 4. Figure 4 shows that ACX-0 beads are flat compared to the other beads, which tend to be more rounded. The average diameter of wet beads obtained was $3.32 \mathrm{~mm}$. After the beads are dried, the diameter of beads decreased up to $159.21 \%$ (Table 2).

Table 2. Wet and dry beads diameter

\begin{tabular}{lll}
\hline Beads & $\begin{array}{l}\text { Wet AVE }(\mathrm{mm}) \pm \\
\text { S.D }\end{array}$ & $\begin{array}{l}\text { Dry AVE }(\mathrm{mm}) \pm \\
\text { S.D }\end{array}$ \\
\hline ACX-0 & $3.36 \pm 0.26$ & $1.67 \pm 0.04$ \\
ACX-1 & $3.25 \pm 0.02$ & $1.28 \pm 0.04$ \\
ACX-2 & $3.42 \pm 0.02$ & $1.14 \pm 0.03$ \\
ACX-3 & $3.24 \pm 0.17$ & $1.15 \pm 0.01$ \\
\hline
\end{tabular}

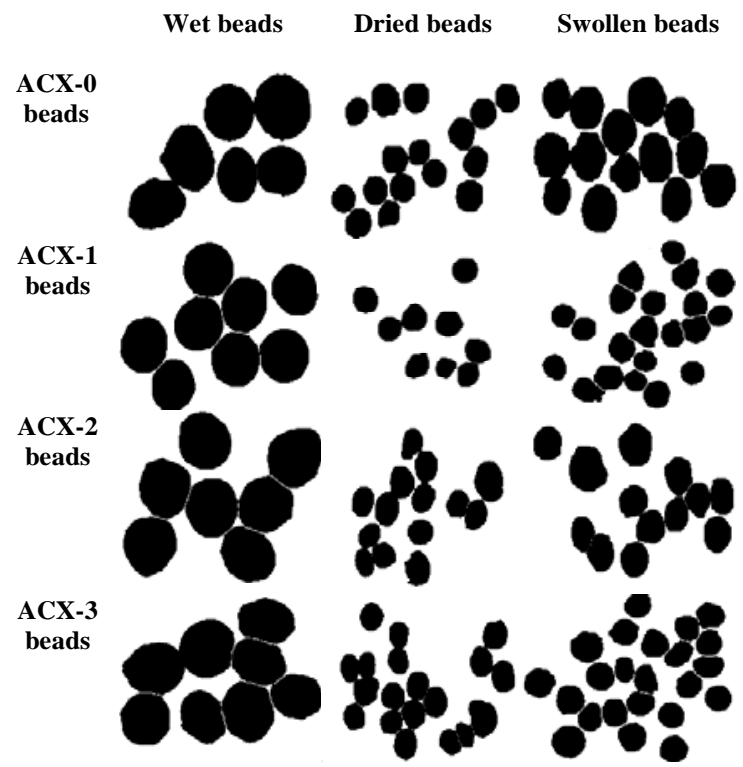

Figure 3. Image analysis of wet, dried, and swollen beads (in water for $24 \mathrm{~h}$ ) beads using Image J

The addition of a porogen to the beads affected the swelling properties and diameter of the beads. Figure 5 shows a graph of changes in the diameter and weight of swollen beads after soaking with distilled water for $24 \mathrm{~h}$. Swelling properties of beads ranged from $35.66-75.73 \%$, while the changes in diameter of the beads ranged from 6.2 - 32.5\%. Swelling properties and diameter increased with increasing porogen concentration. The addition of porogen to the beads also affected the porosity value. The porosity test results obtained (Figure 6) showed that beads porosity increased with increased concentrations of $\mathrm{NaCl}$. ACX-2 and ACX-3 beads had a higher value than ACX-0 beads. In comparison, thereby ACX-1 beads had the lowest porosity of $55.56 \%$.

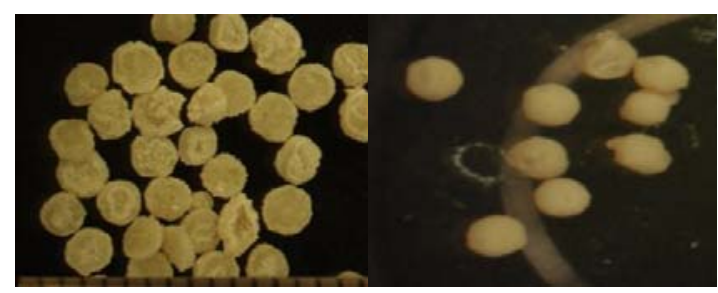

(a)

(b)

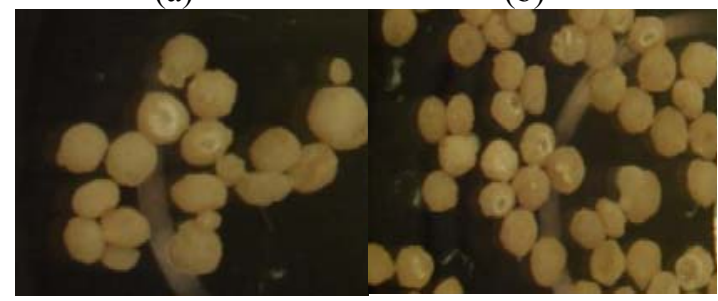

(c)

(d)

Figure 4. Characterization of optical microscope dry beads (a) ACX-0 (b) ACX1 (c) ACX-2 (d) ACX

\section{Surface Morphology}

Figure 7 shows the SEM images of ACX-0 beads (Figure 7a and 7b) and ACX-3 (Figure 7c and $7 \mathrm{~d}$ ). ACX-0 beads had a rough and porous surface with an average diameter of $6.7 \times 10^{-2} \pm$ $0.01 \mu \mathrm{m}$, while the ACX-3 beads had a surface that forms rough folds and several gaps with a diameter of $20.79 \times 10^{-2} \pm 0.03 \mu \mathrm{m}$.

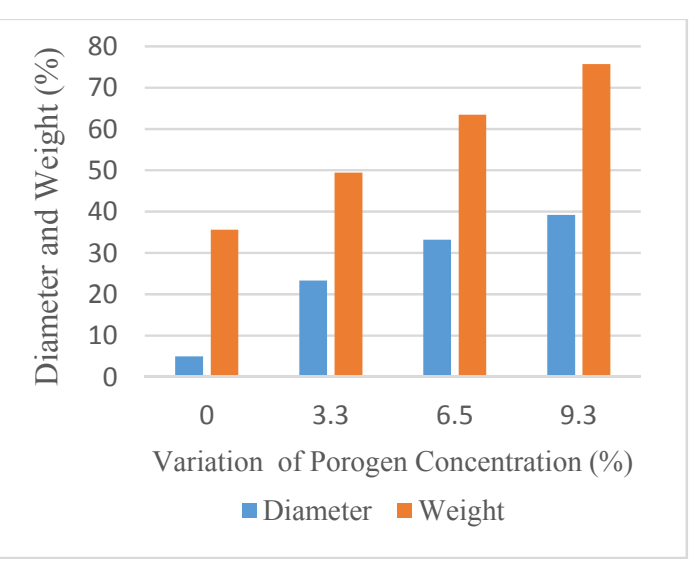

Figure 5. Diameter and weight of swollen beads with different concentrations of porogen 


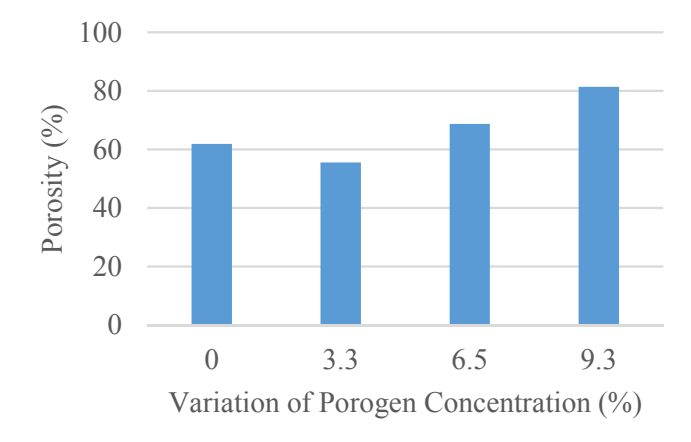

Figure 6. Beads porosity with different concentrations of porogen

\section{Surface Compound}

Based on elemental analysis using EDX as depicted in Figure 8, the following elements were detected on the surface of the beads ACX0 : C, O, H, S, Zn (Figure 8a) while ACX-3 beads had a $\mathrm{Na}$ content of $7.05 \%$ and $\mathrm{Cl}$ of $0.05 \%$ (Figure 8b).

\section{Discussion}

There are two principles of this research. First, the basic ingredients of alginate and cellulose xanthate from cellulose derivatives extracted from corn stalks are the basic ingredients for making beads. The manufacturing technique used was the dropping method. Extraction results showed that lignin was still present in cellulose microfiber because $\mathrm{NaOH}$ used to remove lignin only reacted with ester bonds connecting lignin with hemicellulose in the lignin-carbohydrate (Modenbach, 2013).

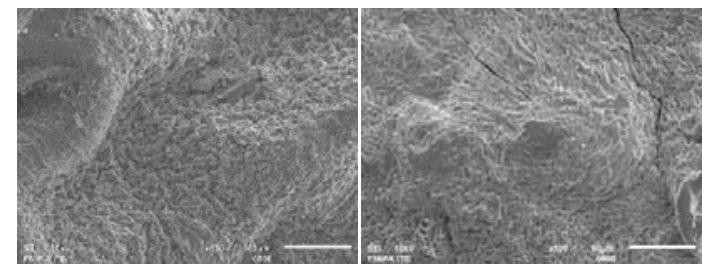

(a)

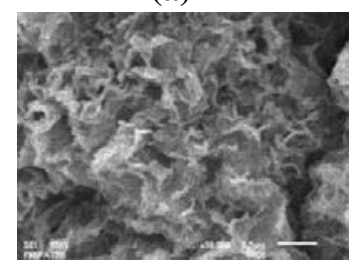

(b) (c)

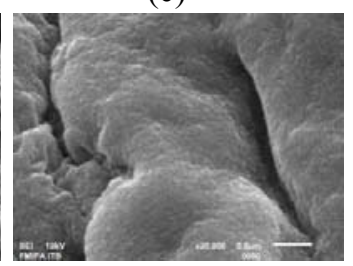

(d)
Figure 7. SEM images of ACX-3 beads (a) 500x magnification, (b) 30000x, and ACX-0 beads (c) 500x magnification, (f) 30000x
Making beads using dropping techniques resulted in a variety of bead sizes (Table 2). The advantage of dropping is that it is easy and inexpensive. However, to produce more uniform beads, it is necessary to consider the injection speed range and the drop distance (Gericke et al., 2012).
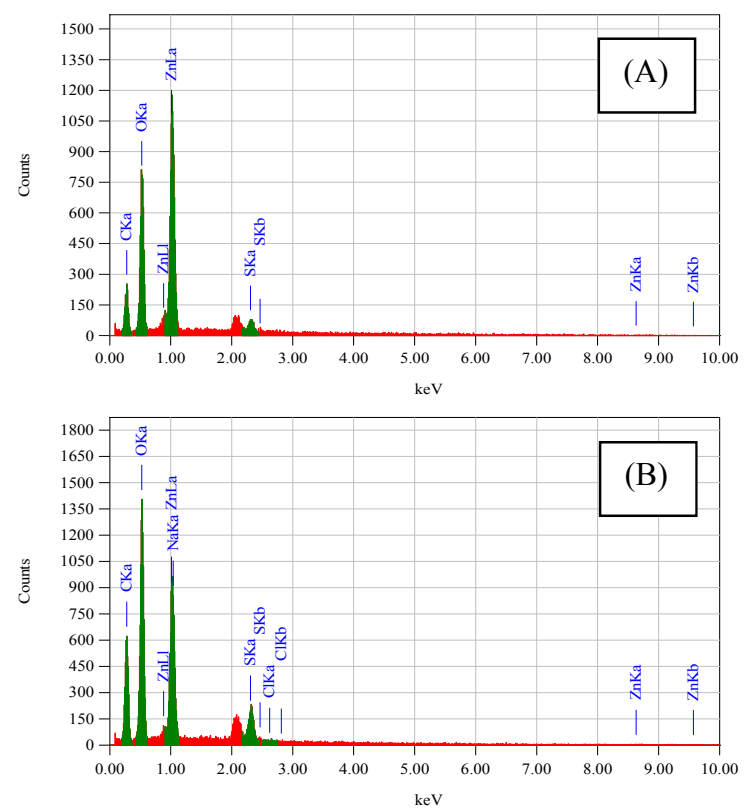

Figure 8. EDX spectra of (A) ACX-0 and (B) ACX-3 beads

Secondly, the feasibility of using $\mathrm{NaCl}$ as a pore-forming agent was assessed in this study. Compared to previous research (Sönmez et al., 2016), with the same material alginate and cellulose as a material for making beads, the addition of $\mathrm{NaCl}$ as porogen could create a rougher and more hollow surface. Increased levels of $\mathrm{NaCl}$ in turn increased the ability of cellulose beads to bind water, which is marked by an increase in swelling and diameter of the beads. This is supported as well by porosity data, which demonstrated increased porosity with increasing levels of the porogen. The presence of porogen caused the space inside the beads to increase thereby increasing the absorption ability of the beads. Beads ACX-1 had a lower porosity than ACX-0. According to $\mathrm{Yu}$ et al. (2008), this could be due to the low concentration of $\mathrm{NaCl}$ porogen, resulting in beads with closed pores and the tendency to be randomly shaped. 


\section{References}

Boufi, S, \& Achraf C. (2016). Easy production of cellulose nanofibrils from corn stalk by a conventional high-speed blender. Industrial Crops \& Products, 93, 39-47.

Datta. R. (1981). Acidogenic Fermentation of Lignocellulose-Acid Yield and Conversion of Components. Biotechnology and Bioengineering, 23, 2167-2170.

Eiselt, P., Yeh, J., Latvala, R.K., Shea, L.D., Mooney, D.J. (2000). Porous carriers for biomedical applications based on alginate hydrogels. Biomaterials, 21, 1921-1927.

Gericke, M., Jani, T., \& Pedro F. (2012). Functional Cellulose Beads: Preparation Characterization and Applications. American Chemical Society.

Harmsen, P. F. H., W. J. J. Huijgen., L. M. B. López., R.R.C. Bakker. (2010). Literature Review of Physical and Chemical Pretreatment Processes for Lignocellulosic Biomass. Food \& Biobased Research, 1-49.

Hokkanen, S., Amit B., \& Mika S. (2016). A review on modification methods to cellulose-based adsorbents to improve adsorption capacity. Water Research, 91, 156-173.

Lee, K.Y., Mooney, D.J. (2012). Alginate: Properties and biomedical applications. Prog. Polym. Sci. Oxf, 37, 106-126.

Lin, N., Cécile B., \& Alain, D. (2012). TEMPOoxidized nanocellulose participating as crosslinking aid for alginate-based sponges. ACS Applied Materials and Interfaces, 4(9), 49484959.

Mane, S. (2016). Effect of Porogens (Type and Amount) on Polymer Porosity: A Review. Canadian Chemical Transaction, 4(2), 210-225.

Modenbach, A. (2013). Sodium hydroxide pretreatment of corn stover and subsequent enzymatic hydrolysis : An investigation of yields, kinetic modelling and glucose recovery. Theses Diss.--Biosyst. Agric. Eng.

Patil, J. S., M. V. Kamalapur., S. C. Marapur., \& D. V. Kadam. (2010). Ionotropic gelation and polyelectrolyte complexation: The novel techniques to design hydrogel particulate sustained, modulated drug delivery system: A review. Digest Journal of Nanomaterials and Biostructures, 5(1), 241-248.

Sönmez, M., Ficai, A., Ficai, D., Trusca, R., Andronescu, E. (2016). Alginate/cellulose composite beads for environmental applications. UPB Sci. Bull. Ser. B Chem. Mater. Sci, 78, 165176.

Suvachittanont, S., Pookingdao, W., (2013). Development of Porous Spherical Cellulose Bead Production from Corn Cob as an Exfoliating Agent for Cosmetic Industries. J. Chem. Chem. Eng., 7, 1156-1163.

Tas, A.C., (2008). Preparation of porous apatite granules from calcium phosphate cement. $J$. Mater. Sci. Mater. Med, 19, 2231-2239. https://doi.org/10.1007/s10856-007-3326-9

Wang, T., Li, B.I.N., Si, H. (2013). Preparation of Regenerated Cellulose Bead and Its Coating With Cyclodextrins. Cellul. Chem. Technol, 47, 37-47.

Wu, Y., Lin, Z.Y., Wenger, A.C., Tam, K.C., Tang, X. (2017). 3D Bioprinting of Liver-mimetic Constructs with Alginate/Cellulose Nanocrystal Hybrid Bioink. Bioprinting.

Yu, H., Howard W. M., Paul H. W., \& Shang, Y. Y. (2008). Effect of Porosity and Pore Size on Microstructures and Mechanical Properties of Poly- $\varepsilon$-Caprolactone-Hydroxyapatite Composites. Journal of Biomedical Materials Research-Part B., 86(2), 541-547.

Zheng, L., Meng, P. (2016). Preparation, characterization of corn stalk xanthates and its feasibility for $\mathrm{Cd}$ (II) removal from aqueous solution. Journal Taiwan Inst. Chem. Eng., 58, 391-400. 